\title{
A EDUCAÇÃO AMBIENTAL NAS LICENCIATURAS: uma análise curricular em uma Instituição de Ensino Superior Pública do Paraná
}

\section{ENVIRONMENTAL EDUCATION IN GRADUATION: a curriculum analysis in} a Paraná's public higher education institution

\author{
Elio Jacob Hennrich Junior 1 \\ Ana Lúcia Olivo Rosas Moreira ${ }^{2}$
}

\section{RESUMO}

A questão ambiental ganha notoriedade pela importância vital que se tem para a vida, dessa forma as escolas ficaram incumbidas de ensiná-la desenvolvendo ideias, petrificando conceitos, para então a prática se tornar diária. Este artigo tem como objetivo analisar os efeitos da educação ambiental na prática dos alunos, seu entendimento sobre meio ambiente, e as possíveis mudanças de comportamento em relação ao consumo desnecessário ou supérfluo. Para isso foi aplicado questionário aos alunos do $3^{\circ}$ ano do ensino médio da Escola Estadual professora Dóris Mendes Trindade - Aquidauana/MS, para verificar a finalidade que dão ao material escolar que ganham do governo. Verificou-se que as mudanças de comportamento mesmo que ainda tímidas já são reais, porém a visão do que é meio ambiente ainda é ingênua.

Palavras-Chave: Formação Docente. Educador Ambiental. Currículo. Ensino Superior.

\section{ABSTRACT}

Owing to the growing needs of working on environmental issues in a holistic and contextualized way, this following paper expatiated about how Environmental Education (EA) is placed throughout the undergraduate curriculum in a Higher Education Institution, comparing them with the state and national policies. Methodologically the research adopted a qualitativequantitative profile of case study, of documentary analysis, and of the simple percentage method to infer some characteristic features of the degrees. It was noticed a limitrophe formation, reflecting on the main difficulties in implementing the EA policies. In this perspective, the assignment of formation must instill the idiosyncrasy of breaking the epistemological obstacles imposed by the environmental crisis.

Keywords: Teacher Formation. Environmental Educator. Curriculum. Higher Education.

\footnotetext{
1 Mestre em de Desenvolvimento Rural Sustentável pela Universidade Estadual do Oeste do Paraná - Campus Marechal Cândido Rondon. E-mail: eliojacobhir@gmail.com

2 Pós-Doutorado pela Universidade do Estado do Paraná- UNESPAR do campus de Paranavaí e pelo Instituto de Educação da Universidade de Lisboa. Professora Associada da Universidade Estadual de Maringá. E-mail: alormoreira@gmail.com
} 


\section{INTRODUÇÃO}

Ao se trazer a tona o debate ambiental é comum o surgimento de discussões também referentes às suas relações com a sociedade atual. Tais questionamentos fazem referência à multicausalidade da crise ambiental, incutida dentro de um cenário mais amplo, uma crise civilizatória.

Perspectivas comumente embasadas por uma visão antropocentrista fragmentada levam a uma concepção reducionista das problemáticas ambientais, exprimindo-se do campo sociocultural, segmentando e reduzindo a complexidade simbólico-ideológica de tais reflexões, orientando-as apenas pelo paradigma da racionalidade técnica ${ }^{1}$ (TEIXEIRA; TORALES, 2014).

A crítica pela utilização da racionalidade técnica à tentativa de resolução dos processos de crise revela uma supervalorização das atividades práticas e técnicas para solucionar a problemática ambiental, que por outro lado ocasiona um esvaziamento das questões socioculturais e consequentemente um desequilíbrio, apenas reproduzindo intervenções, sem o estímulo de reflexões críticas e contextualizadas sobre a problemática ambiental.

Neste sentido, os processos de racionalidade técnica refletem também na forma como a Educação Ambiental (EA) é concebida, uma das principais ferramentas para abordar as discussões ambientais e que acaba em muitos contextos por ser compreendida de forma pontual, buscando alcançar uma "tomada" de consciência espontânea a partir de reflexões antropocentristas (SEVERINO, 2001).

Do mesmo modo, a partir de tal interpretação antropocêntrica, faz-se habitual que em nosso cenário nacional os aspectos centrais da EA sejam orientados e moldados pelo modelo econômico neoliberal vigente, que por consequência orientam suas respectivas políticas ambientais, a cultura ambiental e as formas de se educar ambientalmente (GUERRA, 2014). Além disso, tal discurso neoliberal alusivo às questões ambientais acaba por distanciar os aspectos socioculturais das reflexões ambientais cada vez mais, ditando princípios genéricos e descontextualizados que por sua vez acabam

\footnotetext{
${ }^{1} \mathrm{~A}$ racionalidade técnica relaciona-se com a valorização de paradigmas como o newtonianocartesiano, adotando-a como uma verdade absoluta única e exclusiva para o progresso dos saberes científicos (MAIA, 2015).
} 
por instituir uma EA globalizada (MAIA, 2015).

Porém, a crise ambiental vai muito além da perspectiva neoliberal reducionista e suas atinentes dimensões econômicas, as dimensões socioculturais também são determinantes para a prosperidade dos contextos ambientais, estabelecendo perfis singulares da comunidade com suas respectivas especificidades, trazendo, novamente, a pluralidade e a diversidade como um dos principais elementos da EA.

No debate ambiental não se pode esquecer que o embasamento científico está amparado por uma corrente ideológica, seja ela neoliberal, emancipatória, crítica-reflexiva, dentre outras. Entretanto, diferentemente do modelo tecnicista estanque e engessado proposto pela e hegemonia neoliberal, o presente artigo traz uma ideologia de práxis ambiental como proposição de recurso para enaltecer e dialogar com os perfis dinâmicos dos diferentes contextos socioambientais:

\begin{abstract}
"A filosofia da práxis em seu caráter teórico e prático permite elaborações de cunho científico e filosófico direcionados para a humanização dos homens e mulheres, seu desenvolvimento pleno ao viverem em sociedade. Neste sentido integram-se harmoniosamente reflexão e ação, trabalho e pensamento, sociedade e natureza" (MAIA, 2015, p.288).
\end{abstract}

A segmentação, as divergências, a falta de diálogo e outros fatores inerentes do paradigma newtoniano-cartesiano trazem um grande obstáculo epistemológico na efetiva realização da transversalidade ao se trabalhar a práxis ambiental (SATO, 2001). A existência do ser humano é comumente interpretada de forma limítrofe pelo dualismo entre trabalho e sociedade, deixando de lado a interpretação de cultural e ambiental. Precisamos que o conhecimento, através de uma EA reflexiva, adquira um papel norteador auxiliando na superação da hierarquização economia - sociedade - ambiente - cultura e desenvolva uma nova relação equitativa entre os mesmos (SEVERINO, 2001).

Faz-se necessário, portanto, que gradativamente a visão antropocentrista de crise ambiental, bem como a sua forma de lidar com o meio ambiente, dê lugar a uma concepção holística e biocêntrica, que integre o social e o cultural em tais perspectivas. Não se pode ter uma visão puramente behaviorista e linear da relação entre ambiente e sociedade, é preciso compreendê-los a partir da complexidade das suas relações. Ao se conferir 
uma visão mais holística para tais interações, a EA se torna ferramenta essencial ao longo de tais (re)construções.

A EA se torna relevante a partir do momento que investiga, diagnostica, dialoga, (re)constrói valores e comportamentos sociais, ambientais, políticos, históricos, culturais e econômicos de maneira contextualizada (SEVERINO, 2001). Nesse sentido, a construção de ações ambientais deixa de ser subserviente à economia neoliberal e busca pilares socioambientais para a partir daí (re)pensar os processos de inter-relação sob a ótica socioambiental e concomitantemente a forma de se reflexionar o ambiente por meio de uma EA holística que estabeleça tais valores de uma forma equitativa.

Desta maneira, tais propostas são comumente trazidas por meio de projetos ambientais ou estudos de problemas socioambientais, e uma das principais ferramentas de (re)construção de valores éticos consiste na EA formal, que visa reflexões multidimensionais entre as relações socioambientais. Essas perspectivas vêm sido amplamente sustentadas pela legislação tanto dos âmbitos federais quanto âmbitos estaduais, oportunizando assim uma sistematização mais acurada que efetivamente fortaleça ações integradoras referentes à EA (SOBRINHO, O. P. G. P.; ZANON, A. M., 2016).

Advindo-se então de tais reflexões a presente pesquisa buscou discutir a significação da construção curricular da EA nas licenciaturas e seu respectivo papel na formação inicial de professores. As investigações propostas visaram identificar como a EA se insere ao longo dos currículos das licenciaturas e se intentou identificar as principais contribuições na construção do perfil do docente a ser formado, bem como tais disposições poderão possivelmente influir na atuação dos mesmos ao longo de suas ações ambientais por toda a extensão de seu trabalho docente.

\section{CONTEXTUALIZAÇÃO TEÓRICA}

Para entender o discurso ambiental na sua plenitude holística é preciso se nutrir de uma visão filosófica histórico-crítica que propicie um diálogo por meio do papel educacional da práxis ambiental, a partir de reflexões sociais, políticas, históricas e culturais. Essa forma reflexiva de se abordar a EA vai muito além da usual e rasa concepção de conscientização e sensibilização ambiental, que de forma prolixa acaba por tentar debater a múltipla gama de 
problemas e conflitos ambientais de maneira genérica e descontextualizada, consequentemente impactando a relação da EA nos modelos de ensino que são construídos (MAIA, 2013).

Outro fator que acaba por influenciar a construção de uma EA são as conjunturas dos sistemas educacionais, das múltiplas interpretações sobre os processos de EA, as diferentes compreensões de suas finalidades e como devem ser postas ao longo dos mesmos (KRASILCHIK, 2001).

A identidade de estruturação curricular percorre uma trajetória que possui como cenário principal uma busca por formas de sistematizar ideias, abstrações e conceitos que irão compor as atividades educacionais. As teorizações que estruturam as referidas investigações compõem uma tentativa de ampliar as vias de diálogo entre o conhecimento cultural, o conhecimento científico e o conhecimento educacional (SILVA, 2010).

Nota-se, ainda, uma grande divergência na epistemologia ambiental, onde campos como biologia, pedagogia, sociologia, artes, geografia e história não possuem uma confluência entre o teor educacional e o teor ambiental de suas respectivas práticas educacionais (LEFF, 2001). Dessa forma, há um grande obstáculo na transversalização curricular da práxis ambiental ao longo da ação docente (SATO, 2001).

É praticável extrapolar algumas relações entre as tendências curriculares teóricas com as relações entre educação, sociedade e ambiente ao longo das metodologias de EA em ambientes formais. Lopes e Macedo (2011) trazem uma proposta de inter-relação de conceitos disciplinares aliados a uma aproximação das demandas sociais de cada contexto e juntamente com políticas transversais que respaldam as relações supracitadas.

A pluralidade presente no campo da Educação deve convergir para uma prática social que seja capaz de contemplar as questões norteadas pelas interrelações socioambientais, buscando contribuir para uma interpretação crítica e reflexiva de tais relações situacionais. Além disso, também cabe a educação, mais especificamente à $E A$, que tal criticidade e refletividade oportunizem uma visão global e não globalizada do contexto em que o sujeito está inserido (SEVERINO, 2001).

A EA crítica e reflexiva serve como uma ferramenta para ampliar o canal de diálogo entre sociedade, cultura e ambiente, quebrando a linearidade de 
relação desses valores e os relacionando de maneira complexa e holística. Nesse sentido, é preciso deixar claro quando se trabalha com o perfil educacional, qual o objetivo que se quer ao trabalhar a EA.

Tal forma de se abordar a EA propicia, através de um resgate sociocultural e histórico de como se deram a construção dos problemas e conflitos ambientais, a democratização na participação das construções de diálogos a partir da diversidade dos contextos, enriquecendo equitativamente as construções teóricas e fortalecendo as ações práticas acerca dos pontos comuns e divergências nos desafios socioambientais.

Ao se trabalhar com a pluralidade das diferentes realidades sociais, existe uma inevitabilidade em se adequar a EA às diferentes realidades culturais, políticas e econômicas. Tais necessidades trazem a tona um grande desafio educacional, o de construir uma proposta curricular que efetivamente fortaleça tantas especificidades e que se adéque a diferentes metodologias de ensino (KRASILCHIK, 2001).

Tendo em vista que a educação e o ensino atuam como intercessores nas práticas socioambientais, socioculturais, socio-históricas e políticas, há efetivamente uma convergência e uma coerência de objetivos nos problemas que se querem ser trabalhados.

Aliado a este contexto para o fortalecimento do caráter epistemológico da EA é recorrente a inserção e debate da mesma através de um viés históricocrítico, dialético e reflexivo. Tal perspectiva segundo Teixeira e Torales (2014) busca a superação de alguns obstáculos epistemológicos construídos pelo método antropocêntrico de se trabalhar a EA, (re)construindo a práxis ambiental alicerçando-a com:

- Um perfil histórico - habitualmente construído de maneira multiforme por atributos teórico-metodológicos;

- Heterogeneidade - oportunizar diferentes alternativas de abordagem da temática através dos diferentes contextos socioculturais e socioambientais;

- Políticas públicas - contemplar a referida heterogeneidade de forma a respaldá-la pelas possibilidades político-epistemológicas;

- Mudança socioambiental - estimular uma transição para uma relação dual entre sociedade e natureza em suas diferentes dimensões; 
- Transversalidade - ruptura da linearidade herdada pelo paradigma newtoniano-cartesiano para buscar uma compreensão biocêntrica que conceba a EA para realmente atuar numa resolução contextualizada das diferentes problemáticas ambientais.

Uma epistemologia de EA então que compreenda processos construídos a partir da diversidade, pela multiplicidade e através da contextualização (SATO, 2001), suprindo assim questões referentes às políticas educacionais de EA e se constituindo como elementos que possivelmente sirvam para fundamentar bases socioambientais sólidas nos diferentes níveis educacionais (MAIA, 2015).

Dentro dessa lógica, em conformidade com a Política Nacional de EA, a dimensão ambiental deve se fazer presente em todos os currículos de formação de professores, ao longo dos diferentes níveis de ensino e perpassando por todas as disciplinas (BRASIL, 1999).

Nesse sentido, estabelecer políticas educacionais contextualizadas pode significar um sinônimo de desenvolvimento de ferramentas curriculares para um permanente diálogo socioambiental, que fomentem o protagonismo nas construções de práticas ambientais, fazendo da diversidade e da pluralidade instrumentos para a construção coletiva (SATO, 2001).

Com base em tais reflexões, é preciso interpelar quais instrumentos são necessários para superar tantos obstáculos? Qual perfil educacional ${ }^{2}$ de EA será construído? Como as construções teórico-metodológicas podem influenciar na práxis educacional? (ZUIN; FARIAS; FREITAS, 2009).

Um caminho para sanar tais questionamentos perpassa pelo fomento de ações sustentáveis contíguas que acabem por adotar um perfil efetivo sobre as políticas educacionais institucionais. E para tal, é preciso entender a peculiaridade dos diferentes níveis escolares em seus referentes âmbitos. Assim, é possível entender suas demandas, possibilidades, potencialidades e especificidades (GARCIA, 2006).

Acrescentando a estes fatores, faz-se preciso que a EA ao longo das licenciaturas apresente alternativas para a superação dos obstáculos epistemológicos discutidos anteriormente, sobrepondo o senso comum ambiental, empenhando-se em construir uma indissociabilidade entre os

\footnotetext{
${ }^{2}$ Tecnicista, Comportamentalista, Humanista, Cognitivista e Sociocultural.
} 
campos da práxis ambiental, da sociedade, da política e do histórico-cultural (TEIXEIRA; TORALES, 2014).

Nessa perspectiva, o presente trabalho busca discorrer sobre a forma como a EA se dispõe ao longo dos currículos das licenciaturas em uma Instituição de Ensino Superior (IES), de qual maneira as abordagens pedagógicas contrastam com as políticas de EA nacionais e estaduais, e como as metodologias de ensino estão sendo incorporadas na formação de educadores imbuídos a trabalharem os aspectos socioambientais.

\section{METODOLOGIA}

A seguinte pesquisa adotou um perfil metodológico quali-quantitativo que acompanha assim o perfil holístico de complexidade referente à epistemologia ambiental. Desse modo vale ressaltar a complementaridade entre a análise qualitativa do objeto de estudo juntamente com inferências quantitativas da referente pesquisa (DEMO, 2002).

Inicialmente o escopo metodológico geral de trabalho pode ser categorizado como um estudo de caso, abordagem a qual busca estudar um determinado tipo de evento, procurando conceber através de uma análise interpretativa e integradora uma visão sistêmica dos diferentes elementos que compõem as inter-relações dos fenômenos educativos (MOREIRA, 2011).

Respeitando tal proposição se buscou correlacionar as políticas curriculares da instituição com as disciplinas correlatas à EA, investigando estes elementos educacionais, que por sua vez são interdependentes e indissociáveis. Em adição aos componentes metodológicos qualitativos, a presente investigação também fez uso da análise documental como subsídio auxiliar, segundo Pimentel (2001).

Para tal sistematização, inicialmente, foi promovida uma análise das ementas dos cursos de licenciaturas de uma Instituição de Ensino Superior Pública do Estado do Paraná. Para agregar na sistematização, também foi realizada uma investigação sobre as principais políticas ambientais da instituição, contrastando-as com documentos estruturantes da EA no país, além da forma como os mesmos contribuem para a formação e capacitação de professores quanto à temática ambiental.

A partir de tal sistematização introdutória também foi definido um perfil 
metodológico de âmbito diagnóstico avaliativo para pesquisa, que perpassou pela averiguação da presença da EA ao longo dos currículos de licenciatura da universidade. Dessa maneira, buscou-se uma interpretação holística de como a temática se insere ao longo das ementas curriculares e para isso se faz o uso de cinco palavras-chave: Ambiental; Educação Ambiental; Meio Ambiente; Natureza; Sustentabilidade. As identificações dos vocábulos ao longo destes documentos objetivaram contemplar o contexto trabalhado, possibilitando dessa forma uma sumarização e organização fidedigna perante os dados coletados (GIL, 2008).

Por conseguinte, a inferência quantitativa também foi oriunda da análise das palavras-chave ao longo dos currículos. A abordagem por intermédio de porcentagem então foi escolhida para retratar os dados e auxiliarem nas inferências qualitativas do como a EA permeia as licenciaturas da universidade (MOREIRA, 2011).

Ao se retornar às reflexões acerca da análise documental se nota uma equivalência com a pesquisa bibliográfica no sentido de realizar um levantamento delineado a partir da comparação das fontes de dados ${ }^{3} \operatorname{com}$ os currículos. Nessa perspectiva uma das etapas metodológicas do trabalho consistiu então de uma análise documental que perpassou por um delineamento de seus registros cursivos curriculares, ou o que Gil (2008, p.51) chama de "documentos de segunda mão", elementos que são constituídos através de algum tipo de apreciação analítica.

Para a discussão dos dados investigados se tomou como referência leituras de autores que discorrem a respeito da epistemologia ambiental, da práxis da EA e de como as mesmas podem ser concebidas ao longo do Ensino Superior. Desta forma, tal panorama buscou através do perfil quali-quantitativo a detecção de algumas das dificuldades que se têm ao trabalhar a EA. E a partir de algumas pesquisas relacionadas à EA no Ensino Superior, foi possível inferir como as principais legislações de EA e os demais documentos

\footnotetext{
${ }^{3}$ No cenário desta pesquisa foram utilizadas as seguintes fontes de dados: os Currículos dos Cursos de Licenciatura da Instituição de Ensino Superior; a Política Nacional de Educação Ambiental - PNEA (BRASIL, 1999); o Programa Nacional de Educação Ambiental - ProNEA (BRASIL, 2014); Diretrizes Curriculares Nacionais para Educação Ambiental - DCNEA (BRASIL, 2012) Agenda 30 (ONU, 2016); Política Estadual de Educação Ambiental (PARANÁ, 2013); Decreto Estadual. Os referentes elementos são caracterizados como documentos de primeira mão por Gil (2008, p.51) pois não sofrem qualquer tipo de tratamento analítico.
} 
estruturantes da área educacional impactam na construção curricular da EA ao longo das disciplinas dos cursos de licenciatura da instituição.

\section{RESULTADOS E DISCUSSÕES}

Tomando como referência o que foi discutido anteriormente, é preciso ponderar sobre as atribuições da EA no ensino superior e suas muitas responsabilidades para com a sociedade, trazendo consigo uma busca pela integração ambiental e histórico-cultural para uma maior equidade frente às questões socioambientais (GUERRA, 2014).

Assim, para se cobiçar a excelência na construção e desenvolvimento de ações relativas às políticas ambientais ao longo do ensino superior e ao plano de gestão institucional, deve haver uma convergência no mesmo sentido das políticas públicas, proporcionando uma facilitação ao incorporá-la como uma política institucional.

A solidificação de programas de EA ao longo do ensino superior deve ser estabelecida de forma continuada, refletindo uma dinamicidade na sistematização dos processos educacionais e na construção do currículo (KRASILCHIK, 2001). Em nível local, por exemplo, a Lei n.17505/2013 institui a política estadual de Educação Ambiental e o sistema de Educação Ambiental (PARANÁ, 2013), mais especificamente no âmbito do ensino superior em seu capítulo quinto, subseção II a lei discorre sobre a necessidade das IES integrarem projetos e ações que assegurem a incorporação da EA ao longo de suas administrações. Somando a esta questão, os diferentes níveis de ensino das IES devem inserir conteúdos teórico-metodológicos ${ }^{4}$ que contemplem os pressupostos da EA ao longo de seus currículos pedagógicos, ficando a livre escolha, a forma como a mesma seria inseria e integrada ao longo dos conteúdos pedagógicos dos cursos superiores (PARANÁ, 2013).

Para tal, de acordo com García (2006) em geral as universidades distribuem tais ações e políticas ambientais em cinco eixos:

- O eixo educacional - compreende os cursos de educação formal, seus respectivos currículos e projetos pedagógicos;

\footnotetext{
${ }^{4}$ Parágrafo único. Os instrumentos de implementação devem observar a Carta da Terra, o Tratado de Educação Ambiental para Sociedades Sustentáveis, a Agenda 21 e os demais documentos de referência sobre a educação ambiental (PARANÁ, 2013).
} 
- O eixo de pesquisa - busca trazer uma contextualização teóricometodológica para as ações ambientais, primando pela práxis ambiental ao longo da institucionalização das atividades ambientais da IES;

- O eixo de extensão universitária - atividades direcionadas a prover uma diminuição da vulnerabilidade socioambiental local através de ações construídas a partir da própria práxis ambiental;

- O eixo de ações do campus - diligências que se voltem a diagnosticar e conceber formas pertinentes para se instituir a sustentabilidade ao longo da gestão institucional;

- O eixo de avaliação e comunicação - está ligado com os demais eixos na forma como tais construções de atividades ambientais se comunicam entre si e como são mensuradas;

Tais eixos são amplamente respaldados pelo ProNEA (BRASIL, 2014), que por sua vez traz consigo concepções referentes à EA no ensino superior adotando uma série de critérios e valores que são cruciais para a edificação de um currículo, voltando-se às necessidades críticas e reflexivas de se educar ambientalmente, socialmente, culturalmente e eticamente.

Em consonância com tais afirmações numa conjuntura mais ampla a Lei n.9795/99 que institui a Política Nacional de Educação Ambiental reitera a necessidade de uma EA construída com base nos valores socioambientais, e articulada de forma transversal e interdisciplinar (BRASIL, 1999).

Portanto, ao trabalhar a EA no ensino superior é preciso que haja uma sistematização contínua de tais eixos, buscando otimizar a formação profissional de docentes e servidores em geral. Dessa forma, oportunizando o cumprimento do que foi estabelecido nas diretrizes norteadoras das políticas ambientais no ensino superior: relação sociedade-ambiente, equidade socioambiental e ética ambiental (JUNYENT; GELI; ARBAT, 2003).

Reiterando essa perspectiva, o artigo 21 das DCNEA traz que:

"Os sistemas de ensino devem promover as condições para que as instituições educacionais se constituam em espaços educadores sustentáveis, com a intencionalidade de educar para a sustentabilidade socioambiental de suas comunidades, integrando currículos, gestão e edificações em relação equilibrada com o meio ambiente, e tornandose referência para seu território" (BRASIL, 2012, p.7). 
Isto posto, a solidificação da EA no ensino superior também perpassa pelos currículos dos cursos, que necessitam integrar tanto conceitos quanto metodologias que possibilitem a operacionalização para a realização de atividades relacionadas com a prática pedagógica da EA em conjunto com ações que propiciem entender e apreciar o ambiente e sua complexidade (GUERRA, 2014). Partindo de tal reflexão, faz-se necessário clarificar o objetivo dos projetos curriculares para que a partir desse se possam analisar as necessidades e desafios interpostos para a implementação de uma EA que eduque para a sustentabilidade.

É preciso, por consequência, uma análise integral da relação EA - IES onde seja amparada nas principais políticas e documentos estruturantes que norteiam os cursos de licenciatura bem como a IES. Deve-se construir uma EA institucional no ensino superior "para" e "pela" universidade, com uma gestão que propicie ensino, pesquisa e extensão coordenados pelos princípios teóricometodológicos da EA (BRASIL, 2012).

Ainda nesse panorama, Zuin et al. (2009) ressalta a importância de se investigar como a construção curricular da EA ao longo das licenciaturas, tanto nas áreas de conhecimento específico quanto nas disciplinas de cunho pedagógico (tabela 1), está relacionada com as políticas de EA nacionais e estadual. Assim, a partir de tais contextos políticos é que se faz possível construir currículos de licenciatura na IES.

É nesse sentido que a análise dos cursos de licenciatura da IES analisada na pesquisa (tabela 1) possibilitou uma abrangente ferramenta de análise com base na ampla distribuição de dados referentes às principais características dos currículos dos cursos de licenciatura.

Mesmo possuindo um caráter de diagnóstico local devido às especificidades do contexto estudado, ao se reflexionar como a EA perpassa os currículos das licenciaturas dentro da Universidade é possível estabelecer uma oportunidade de se debater novas perspectivas que, por muitas vezes, são comuns em diferentes panoramas, por serem construídos a partir de uma mesma concepção (SATO, 2001). 
Tabela 1: Cursos da IES pública que abordam de forma direta ou indireta a temática ambiental.

\begin{tabular}{|c|c|c|c|}
\hline Curso & Turno & Disciplina & $\mathrm{C} / \mathrm{H}$ \\
\hline Artes Cênicas & Vespertino & Políticas Públicas na Educação Brasileira & $68 \mathrm{~h}$ \\
\hline $\begin{array}{l}\text { Ciências } \\
\text { Biológicas }\end{array}$ & $\begin{array}{l}\text { Integral/ } \\
\text { Noturno }\end{array}$ & $\begin{array}{l}\text { Educação, Sociedade e Meio Ambiente }^{5} \\
\text { Biologia Sanitária } \\
\text { Biotecnologia }^{5} \\
\text { Ecologia Sistêmica } \\
\text { Microbiologia } \\
\text { Biologia de Campo I } \\
\text { Biologia de Campo } \text { II }^{5} \\
\text { Biologia e Sociedade } \\
\text { Biotecnologia e Ambiente }{ }^{5} \\
\text { Educação formal e informal em museus e centros de } \\
\text { ciências } \\
\text { Interfaces entre Antropologia e Biologia }{ }^{5} \\
\text { Instrumentação para o Ensino de Biologia } \\
\text { Instrumentação para o Ensino de Ciências } \\
\text { Introdução às Ciências Biológicas } \\
\text { Políticas Públicas e Gestão Educacional }\end{array}$ & $\begin{array}{l}68 \mathrm{~h} \\
68 \mathrm{~h} \\
68 \mathrm{~h} \\
85 \mathrm{~h} \\
68 \mathrm{~h} \\
34 \mathrm{~h} \\
34 \mathrm{~h} \\
68 \mathrm{~h} \\
34 \mathrm{~h} \\
68 \mathrm{~h} \\
68 \mathrm{~h} \\
68 \mathrm{~h} \\
68 \mathrm{~h} \\
68 \mathrm{~h} \\
34 \mathrm{~h} \\
68 \mathrm{~h}\end{array}$ \\
\hline $\begin{array}{l}\text { Ciências } \\
\text { sociais }\end{array}$ & Noturno & $\begin{array}{l}\text { Sociologia Ambiental } \\
\text { Políticas Públicas e Gestão Educacional }\end{array}$ & $\begin{array}{l}68 \mathrm{~h} \\
68 \mathrm{~h}\end{array}$ \\
\hline $\begin{array}{l}\text { Educação } \\
\text { física }\end{array}$ & $\begin{array}{l}\text { Integral/ } \\
\text { Noturno }\end{array}$ & $\begin{array}{l}\text { Esportes de Aventura no Ambiente Terrestre } \\
\text { Teorias do Lazer } \\
\text { Lazer na Natureza }^{5}\end{array}$ & $\begin{array}{l}68 \mathrm{~h} \\
102 \mathrm{~h} \\
68 \mathrm{~h}\end{array}$ \\
\hline Filosofia & Vespertino & Políticas Públicas e Gestão Educacional & $68 \mathrm{~h}$ \\
\hline Física & Noturno & Políticas Públicas e Gestão Educacional & $85 \mathrm{~h}$ \\
\hline Geografia & $\begin{array}{l}\text { Matutino/ } \\
\text { Noturno }\end{array}$ & $\begin{array}{l}\text { Biogeografia Geral } \\
\text { Geografia do Turismo }^{5} \\
\text { Uso e manejo dos Recursos Naturais } \\
\text { Geografia Regional do Brasil } \\
\text { Geografia Urbana } \\
\text { Biogeografia em Ambientes Urbanos } \\
\text { Geomorfologia aplicada }\end{array}$ & $\begin{array}{l}68 \mathrm{~h} \\
68 \mathrm{~h} \\
68 \mathrm{~h} \\
68 \mathrm{~h} \\
96 \mathrm{~h} \\
68 \mathrm{~h} \\
34 \mathrm{~h}\end{array}$ \\
\hline História & Noturno & $\begin{array}{l}\text { Patrimônio Cultural I } \\
\text { História da Alimentação }^{5}\end{array}$ & $\begin{array}{l}68 \mathrm{~h} \\
68 \mathrm{~h} \\
\end{array}$ \\
\hline Letras & $\begin{array}{l}\text { Matutino/ } \\
\text { Noturno } \\
\end{array}$ & Políticas Públicas e Gestão Educacional & $68 \mathrm{~h}$ \\
\hline Matemática & $\begin{array}{l}\text { Integral/ } \\
\text { Noturno }\end{array}$ & Políticas Públicas e Gestão Educacional & $68 \mathrm{~h}$ \\
\hline Música & Integral & Políticas Públicas e Gestão Educacional & $68 \mathrm{~h}$ \\
\hline Pedagogia & $\begin{array}{l}\text { Matutino/ } \\
\text { Noturno }\end{array}$ & $\begin{array}{l}\text { Políticas Públicas e Gestão da Educação Brasileira } \\
\text { Metodologia para o Ensino de Geografia } \\
\text { Metodologia do Ensino de Ciências: } 1^{\underline{a}} \text { a } 4^{\underline{a}} \text { séries do } \\
\text { Ensino Fundamental I } \\
\text { Metodologia do Ensino de Ciências: } 1^{\text {a }} \text { a } 4^{\underline{a}} \text { séries do } \\
\text { ensino fundamental II }\end{array}$ & $\begin{array}{l}34 \mathrm{~h} \\
68 \mathrm{~h} \\
34 \mathrm{~h} \\
34 \mathrm{~h}\end{array}$ \\
\hline Química & Noturno & $\begin{array}{l}\text { Química Ambiental } \\
\text { Políticas Públicas e Gestão Educacional }\end{array}$ & $\begin{array}{l}68 \mathrm{~h} \\
34 \mathrm{~h}\end{array}$ \\
\hline \begin{tabular}{l}
\multicolumn{2}{l}{ Licenciatura } \\
plena em \\
Ciências
\end{tabular} & Noturno & $\begin{array}{l}\text { Ciências do ambiente } \\
\text { Sociologia } \\
\text { Políticas Públicas e Gestão Educacional }\end{array}$ & $\begin{array}{l}136 h \\
68 h \\
68 h\end{array}$ \\
\hline
\end{tabular}

Fonte: Dados organizados pelo autor.

Nessa acepção dos 15 cursos de licenciatura na modalidade presencial da universidade apenas o curso de Artes Visuais não apresenta qualquer tipo

\footnotetext{
${ }^{5}$ Disciplinas optativas do curso.
} 
de disciplina que aborde de forma direta ou indireta a temática ambiental de acordo com as palavras-chave ${ }^{6}$ que foram usadas como ferramenta de busca.

A estruturação de conteúdos e práticas pedagógicas relacionadas à $E A$ permite a efetivação de ferramentas que oportunizem através da pluralidade epistemológica da EA a superação da linearidade positivista existente na EA. Ao se incentivar tais incorporações teórico-práticas as cargas subjetivistas e dialéticas viabilizam um diálogo holístico e interdisciplinar das licenciaturas, que perpassam pelas múltiplas idealizações relativas à $E A$.

Ao examinar a efetividade da implementação das legislações se nota que ainda existe uma grande lacuna entre a teorização destas leis até a sua implementação. E o preenchimento de tais hiatos se dá pelos contextos, significados, epistemologias e hibridismos (ZUIN; FARIAS; FREITAS, 2009).

Conforme indica o ProNEA, faz-se necessário incorporar ao longo dos projetos político-pedagógicos dos cursos e suas respectivas ementas de disciplina um enfoque ambiental que estejam em concordância com as demais leis e diretrizes de EA e, que também sejam capazes de dialogar com os âmbitos de ensino, pesquisa e extensão (BRASIL, 2014).

Tal asserção também está em conformidade com as DCNEA, que reafirmam a EA como um elemento essencial e permanente dos currículos, permeando tanto a promoção de uma qualificação de docentes do ensino superior quanto dos seus respectivos licenciandos. A formação de profissionais capacitados proporciona uma melhor qualificação para se trabalhar interdisciplinarmente a $\mathrm{EA}$, de forma holística e reflexiva nos diferentes níveis educacionais (BRASIL, 2012).

O currículo das licenciaturas deve, portanto, ser um caminho holístico para que se instrumentalize a construção socioambiental, política, teóricometodológica e cultural para a formação de sujeitos ambientalmente reflexivos (KRASILCHIK, 2001).

O PNEA orienta que a EA seja instituída de forma integrativa e continuada, refutando a disciplinaridade da mesma, porém esta pode ser concebida como uma forma de inserção inicial da temática, a fim de posteriormente se construir de forma permanente uma EA reflexiva, crítica e

\footnotetext{
${ }^{6}$ Ambiental, Educação Ambiental, Meio Ambiente, Natureza e Sustentabilidade. Os critérios estabelecidos foram discutidos na seção de metodologia deste trabalho.
} 
embasada na racionalidade ambiental (TEIXEIRA; TORALES, 2014). Somando às recomendações do ProNEA, que aponta a proposta de incluir disciplinas que cooperem na construção de concepções ambientais durante a formação dos licenciandos, perpassando por todo o currículo do curso, através de diálogos transversais (BRASIL, 2014).

Neste panorama de transversalidade trazido pelos documentos norteadores de EA, observou-se que das 44 disciplinas analisadas (tabela 1) incluem em sua ementa alguma menção direta ou implícita às palavras-chave utilizadas na metodologia e como temática de suas práticas docentes. No entanto, ainda é essencial que haja efetivamente uma proposta pedagógica concreta sobre como se trabalhar a EA nos cursos de licenciatura, com uma contextualização de acordo com a realidade da IES, que preconiza um adequado aporte teórico-metodológico sobre tais questões.

Verificou-se também que a EA nas licenciaturas da universidade se dispõe habitualmente na forma semestralizada. Ou seja, 32 das 43 disciplinas que possuem algum teor de discussão ambiental (72\%), apresentam uma carga horária de $68 \mathrm{~h}$, usualmente distribuídas em duas ou três aulas semanais. Apenas duas disciplinas (4,7\%) estão dispostas anualmente. Observa-se que o currículo ainda, muitas vezes, é conduzido a uma tendência tecnicista, perdendo a visão humanista e sociocultural na implementação do debate ambiental ao longo dos cursos. O que se tem como EA nas licenciaturas e, consequentemente ao longo dos processos de formação de professores, é, ainda majoritariamente, uma concepção limítrofe, refletindo dessa maneira nas principais dificuldades em se implementar as políticas de EA.

Uma complexidade teórico-metodológica contribui para uma percepção de práxis ambiental contextualizadora, permeando as individualidades dos diferentes cursos de licenciatura. Mais uma vez é relevante ressaltar a necessidade de um equilíbrio entre o conhecimento teórico e as ações práticas para convergir a uma práxis educacional que melhor se condicione ao cenário ambiental da instituição (TEIXEIRA; TORALES, 2014).

Por essa razão, o processo de equiparação teórico-prática deve ocorrer não somente na esfera curricular, mas nas diferentes instâncias do processo educativo, requerendo, assim, a ampliação do conceito de EA no ensino superior. Ou seja, envolvendo não só o currículo, mas a pesquisa, a extensão e 
a gestão ambiental da IES num processo contínuo e dinâmico. Desta maneira, fica evidente a necessidade em que as políticas ambientais das universidades estejam sintonizadas e em articulação com as políticas públicas em Educação Ambiental e meio ambiente (FIGUEIREDO; GUERRA; CARLETTO, 2014).

Conforme as Diretrizes Curriculares Nacionais para a EA (BRASIL, 2012) são princípios elementares: holismo, concepção biocêntrica de ambiente, construção de uma práxis educativa plural, transversalidade da EA ao longo de todo ensino superior e a contextualização das práticas pedagógicas com a realidade ambiental local, regional, e global, estes devem ser contemplados em cursos para a formação e a qualificação de educadores.

\section{CONCLUSÃO}

Ao analisar os documentos estruturantes de um curso, neste caso específico das licenciaturas, buscamos considerar e refletir sobre questões como: a forma como o curso se organiza; quais as principais características das ementas do curso e de suas referentes disciplinas; a organização das matrizes curriculares; entre outras generalidades. A partir do momento em que se buscou correlacionar as referidas questões ao longo das licenciaturas investigadas, foi possível extrapolar que os mesmos podem acabar influenciando tanto na atuação docente, quanto na construção do perfil dos licenciandos.

As fundamentações teórico-medológicas das ementas curriculares podem por consequência se correlacionar de maneira progressiva com a formação dos licenciandos, implicando na forma como as suas respectivas construções epistemológicas irão alicerçar a sua futura práxis de EA.

Deste modo a tarefa de se formar um futuro professor que tenha incutido em seu perfil docente a idiossincrasia de ser um educador ambiental advém de proporcionar não somente ferramentas para que haja o rompimento dos obstáculos epistemológicos, mas também interpretações socioambientais contextualizadas. A construção continuada de perspectivas holísticas e dialógicas ao longo da EA proporciona uma correlação interpretativa da práxis, organizando alternativas e ferramentas para a superação multicausal da crise ambiental. 
Com isso, ao proporcionar discussões como essas levantadas na presente pesquisa sobre princípios ambientais educacionais incutidos nos currículos, expressa-se reflexões fundamentais na construção do perfil do educador. A discussão das conformações curriculares e de como a EA se estabelece ao longo dos mesmos torna possível a superação de dificuldades em se trabalhar a práxis ambiental.

Assim sendo, é essencial para uma efetiva implementação da EA de maneira transversal oportunizar aportes teórico-metodológicos que respaldem formas de se notabilizar a pluralidade epistemológica da EA, além de buscar modos para se interpretar e conceber a interação holística entre o sujeito e ambiente ao longo da formação docente no Ensino Superior. 


\section{REFERÊNCIAS}

BRASIL. Política Nacional de Educação Ambiental. Lei №.9795/99. Diário Oficial da República Federativa do Brasil, Brasília, DF, 27 abr. 1999. Disponível em: <www.planalto.gov.br/ccivil 03/Leis/L9795.htm>. Acesso em: 10 jul. 2018.

BRASIL. Conselho Nacional de Educação. Resolução no 2, de 15 de junho de 2012. Estabelece as Diretrizes Curriculares Nacionais para a Educação Ambiental. Brasília, 2012. Disponível em: $<$ http://portal.mec.gov.br/index.php?option=com content\&id=17810\&ltemid=86 6r>. Acesso em: 25 jun. 2018.

BRASIL. Programa Nacional de Educação Ambiental. Ministério do Meio Ambiente e Ministério da Educação. Brasília: MMA e MEC, 2014. 4.ed. 113p. Disponível em: <http://www.mma.gov.br/publicacoes/educacaoambiental/category/98-pronea>. Acesso em: 01 ago. 2018.

DEMO, P. Avaliação qualitativa. 7.ed. Campinas: Autores Associados, 2002.

GARCÍA, F. J. L. Sustainability in higher education: what is happening?. Journal of Cleaner Production, Knoxville, v. 14, p. 757-760, 2006. Disponível em: <https://www.sciencedirect.com/science/article/pii/S095965260600014X>. Acesso em: 1 out. 2018.

GIL, A. C. Métodos e Técnicas de Pesquisa Social. 6. ed. São Paulo: Atlas, 2008.

GUERRA, A. F. S.; FIGUEIREDO, M. L. Ambientalização curricular na Educação Superior: desafios e perspectivas. Educar em Revista, Curitiba, Brasil, Edição Especial n. 3, Editora UFPR, p. 109-126, 2014. Disponível em: <http://www.scielo.br/pdf/er/nspe3/a08nspe3.pdf>. Acesso em: 10 set. 2018.

JUNYENT, M.; GELI, A. M.; ARBAT, E.. Características de la ambientalización curricular: Modelo ACES. In: JUNYENT, M.; GELI, A. M.; ARBAT, E.(Orgs.). Ambientalización Curricular de los Estudios Superiores. Proceso de Caracterización de la Ambientalización Curricular de los Estudios Superiores. Girona: Universitat de Girona - Rede ACES,. v. 2, p. 15-32, 2003. Disponível em: <http://www3.udg.edu/ov/Comunicacio/docs/Aces2/02Capitol1.pdf >. Acesso em: 22 out. 2018.

KRASILCHIK, M. Pesquisa em Educação Ambiental: tendências e percepção ambiental. Educação Teoria e Prática, v.9, n.16-17, p.43-45, 2001.

LEFF, E. Epistemologia Ambiental. Tradução de Sandra Valenzuela; revisão de Paulo Freire Vieira. São Paulo: Cortez, 2001. 240 p.

LOPES, A. C.; MACEDO, E. Teorias de Currículo. São Paulo: Cortez, 2011, $280 \mathrm{p}$.

MAIA, J. S. Problemáticas da Educação Ambiental no Brasil: elementos para a reflexão. Revista Eletrônica do Mestrado em Educação Ambiental - 
REMEA, v.32, n.2, p. 283-298, jul/dez 2015. Disponível em: $<$ https://periodicos.furg.br/remea/article/view/5544>. Acesso em: 15 ago. 2018.

MOREIRA, M. A. Metodologias de Pesquisa em Ensino. São Paulo: Livraria da Física, 2011.

NAÇÕES UNIDAS NO BRASIL- ONU BR. A Agenda 2030. Disponível em: <https://nacoesunidas.org/pos2015/agenda2030/>. Acesso em: 22 out. de 2018

OLIVEIRA JUNIOR, W. M. de; GARGALLO, J. B.; AMORIM, A. C. R.; ARBAT, E. As 10 características em um diagrama circular. In: JUNYENT, M.; GELI, A. M.; ARBAT, E.. (Eds.). Ambientalización Curricular de los Estudios Superiores: aspectos Ambientales de les universidades. 2: proceso de caracterización de la Ambientalización Curricular de los Estudios Universitarios. Girona: Universitat de Girona, v. 2, p. 35-55, 2003. Disponível em: < http://www3.udg.edu/ov/Comunicacio/docs/Aces2/03Capitol2.pdf >. Acesso em: 4 jun. 2018.

PARANÁ. Lei no. 17505 de 11 de Janeiro de 2013. Institui a Política Estadual de Educação Ambiental e o Sistema de Educação Ambiental e adota outras providências. Governo do Estado do Paraná. 2013. Disponível em: $<$ http://www.legislacao.pr.gov.br/legislacao/pesquisarAto.do?action=exibir\&cod Ato $=85172>$. Acesso em: 27 ago. 2018.

SATO, M. Apaixonadamente Pesquisadora em Educação Ambiental. Educação Teoria e Prática, v.9, n.16-17, p.24-35, 2001.

SEVERINO, A. J. A Relevância Social e a Consistência Epistêmica da Pesquisa em Educação: alguns subsídios para se avaliar a pesquisa em Educação Ambiental. Educação Teoria e Prática, v.9, n.16-17, p.10-16, 2001.

SILVA, T. T. da. Documentos de Identidade: Uma Introdução às Teorias de Currículo. $3^{\circ}$ Edição. Editora Autêntica. 2010.

SOBRINHO, O. P. G. P.; ZANON, A. M. Dos sentidos à abordagem integradora da Educação Ambiental no contexto formal de ensino. Ambiente \& Educação, v, 21, n. 1, p. 94-110, 2016. Disponível em:

<https://periodicos.furg.br/ambeduc/article/view/6100/3984>. Acesso em: 24 out. 2018.

TEIXEIRA, C.; TORALES, M. A. A questão ambiental e a formação de professores para a educação básica: um olhar sobre as licenciaturas. Educar em Revista, Curitiba, Brasil, Edição Especial n. 3, p. 109-126, 2014. Disponível em: <https://revistas.ufpr.br/educar/article/view/38111>. Acesso em: 9 ago. 2018.

ZUIN, V. G.; FARIAS, C. R.; FREITAS, D. de. A ambientalização curricular na formação inicial de professores de Química: considerações sobre uma experiência brasileira. Revista Electrónica de Enseñanza de las Ciencias, v. 8, n. 2, 2009. Disponível em: $<$ http://reec.uvigo.es/volumenes/volumen8/ART10 Vol8 N2.pdf >. Acesso em: 
ISSN- 1413-8638

E-ISSN - 2238-5533

v. 24, n. 2, 2019

28 jun, 2018, 